\title{
Filosofias DO TEMPO: \\ CIRCULARIDADE, \\ SUJEITO E OBJETIVAÇÃO
}

\author{
Victor Leandro Silva* \\ Daniel Richardson de Carvalho Sena**
}

\begin{abstract}
RESUMO
0 presente artigo visa discutir a problemática filosófica do tempo a partir das perspectivas dos filósofos Empédocles e Kant, enfatizando o caráter cíclico do primeiro e as condições subjetivas de realização da temporalidade do segundo. Com isso, pretende-se não somente enfatizar a acuidade organizativa de seu conceito, como também verificar de que modo esses aspectos dialogam com expressões significativas temporais da contemporaneidade, em que se destaca o pensamento do filósofo francês Bernard Stiegler, para quem as mudanças socioeconômicas são de relevância precípua para a constituição de uma nova perspectiva temporal, dessa vez regida por elementos externos que ameaçam decisivamente a individualidade dos diversos sujeitos.
\end{abstract}

Palavras-chave: tempo, ciclo, sujeito, objetos industriais temporais.

* ORCID iD https://orcid.org/0000-0002-9758-5249. UEA - Universidade do Estado do Amazonas. Licenciado em filosofia pela UFAM. Doutor em Sociedade e Cultura na Amazônia pela Universidade Federal do Amazonas. Professor Adjunto da Universidade do Estado do Amazonas. viktorleandro@hotmail.com .

** ORCID iD https://orcid.org/0000-0002-6085-7650 . IFAM . Licenciado em Filosofia. Mestre em Ciências do Ambiente e Sustentabilidade na Amazônia pela UFAM. Professor do IFAM. daniel.sena@ifam.edu.br . 


\title{
Philosophies of TIME: CIRCUlarity, SUBJECT AND OBJECTIFICATION
}

\begin{abstract}
The present article aims to discuss the philosophical problematic of time from the perspectives of the philosophers Empedocles and Kant, emphasizing the cyclical character of the first and the subjective conditions of realization of the temporality of the second. Then, it is intended not only to emphasize the organizational accuracy of its concept, but also to verify how these aspects dialogue with significant temporal expressions of contemporary times, in which the thinking of the French philosopher Bernard Stiegler stands out, for whom socioeconomic changes are of primary relevance for the constitution of a new temporal perspective, this time governed by external elements that decisively threaten the individuality of the various subjects.
\end{abstract}

Keywords: Time, Cycle, Subject, Temporal Industrial Objects.

\section{INTRODUÇÃo}

A ideia de tempo, bem como suas implicações sobre a vivência dos indivíduos, sempre ocupou uma parte significativa da tradição filosófica, conduzindo pensadores de várias épocas a elaborar conceituações que pudessem dar conta das diversas problemáticas advindas dessa reflexão.

Aliado a isso, encontramos também as múltiplas transformações culturais, que, a despeito das considerações objetivas delimitadas pelos físicos, propõem questionamentos que ficam para além de sua alçada, uma vez que atingem o plano experiencial do sujeito, no que a filosofia mais uma vez aparece como um dos principais mecanismos de sua elucidação.

Desse modo, é no pensar filosófico que encontramos o esteio para pensar a progressão de nossa experiência temporal, em especial nas noções que antagonizam externalidade e subjetividade, as quais se mostram extremamente caras para a análise de expressões contemporâneas do tempo, em que a égide do econômico se mostra deletéria das formações do individual. 


\section{EMPÉDOCLES: CICLOS ETERNOS DE GERAÇÃO E CORRUPÇÃo}

Algumas culturas da antiguidade adotavam uma representação do tempo não linear, afirmando a existência de ciclos repetitivos, intrínsecos ao surgimento e à extinção de todos os seres do mundo físico. Nessa perspectiva, o universo, o mundo e os seres não são fruto de uma criação originária, mas de uma transformação perpétua, onde não há começo nem fim. Essa forma de representação da realidade está presente na filosofia grega antiga, podendo ser encontrada no pensamento de Empédocles, mais precisamente em sua doutrina sobre uma sequência cósmica ininterrupta de geração e corrupção.

Empédocles foi um filósofo do chamado Período Pré-Socrático ou Cosmológico do pensamento grego antigo. Teria vivido na cidade de Agrigento, hoje pertencente ao território da Sicília, sul da Itália. Supõe-se que sua vida transcorrera entre os anos de 492 a 432 a. C. Conforme Diógenes Laércio (1987), historiados e biógrafo dos pensadores da antiguidade, Empédocles pertencia à elite de sua cidade e teria sido um famoso médico. Muitas lendas e exageros constituem as histórias (ou estórias) sobre a vida deste pensador, como a de que este possuiria poderes mágicos, que dominaria os ventos e teria ressuscitado uma mulher.

Empédocles escreveu três obras: "Da Natureza", "Purificações" e um "Tratado Sobre a Medicina”. Destas obras, nos restam apenas fragmentos. Dentre os pré-socráticos, Empédocles é considerado um filósofo pluralista, pois, diferentemente dos demais, afirmava a existência de quatro elementos ou archés, responsáveis pela origem e ordenação da physis ou natureza, donde sua mutação constante não cessa, implicando diretamente no ordenamento do cosmos. Segundo Aristóteles, "Empédocles foi o primeiro a afirmar que são quatro os elementos atribuídos à natureza material" (ARISTÓTELES, 1973, p. 220).

No fragmento seis, da obra "Da Natureza", Empédocles cita metaforicamente a existência desses quatro elementos originários: "Ouve primeiro das quatro raízes de todas as coisas: Zeus brilhante, Hera vivificante, e Aidoneus e Netis, que deixa correr de lágrimas tua fonte terrena" (BORNHEIM, 2000, p. 68).

Diógenes Laércio (1987), explica que por Zeus, Empédocles identifica o fogo, por Hera a terra, por Aidoneus o ar e por Netis, a água. 
De acordo com Kirk, Raven \& Schofield (2010), a caracterização dos quatro elementos como deuses propõem-se, possivelmente, sugerir o que há de correto no entendimento tradicional sobre as divindades, como também reivindicar, poderes e propriedades que os tornam dignos de receio e reverência por parte dos mortais.

Estima-se que seu pensamento sofrera a influência de outros pré-socráticos. Conforme Osborne (2013), Empédocles teria seguido algumas das crenças defendidas por Pitágoras; Diógenes Laércio (1987), por sua vez, relata que o mesmo mantinha admiração por Parmênides. Porém, é possível afirmar que sua filosofia não pertencia diretamente a nenhuma escola em particular, mas, semelhante aos pensadores de seu tempo, preocupava-se primordialmente com o problema da origem do Ser, de sua permanência e transformação.

É possível perceber também em sua doutrina a existência de elementos ecléticos. Isto é, aparentemente Empédocles tencionava conciliar o monismo de Parmênides com a teoria do perpétuo devir de Heráclito. Kirk, Raven \& Schofield (2010) enfatizam que Empédocles reconhecia na obra de Parmênides um desafio epistemológico radical à cosmologia, fato que o obrigou a assumir uma posição, desenvolvendo dessa maneira um espírito heraclitiano. Sobre este ponto, Mondin explica que:

Empédocles é de opinião, como Parmênides, que o ser é imutável, porque se não o fosse, o mundo já teria deixado de existir. Afirma com os Jônios, que o princípio primordial das coisas não deve ser posto em algo diverso do mundo, mas nos quatro elementos (terra, fogo, água e ar): não em um só, mas nos quatro ao mesmo tempo. Os elementos não derivam um do outro, como ensinavam os jônios, mas são absolutamente originais e imutáveis. Por isso, cada um deles espelha os caracteres de imobilidade que Parmênides atribuía ao ser... o devir é possível não pela transformação dos elementos, mas pela formação dos seres diferentes mediante a combinação diversa dos elementos. (MONDIN, B. 2008, p. 35).

A existência de ciclos responsáveis pelo movimento, transformação, geração e corrupção das coisas, bem como pelo surgimento e desaparecimento das mesmas, encontra-se presente no fragmento dezessete da obra "Da Natureza". Empédocles explica que a união e a 
separação dos elementos responsáveis pela geração e pela destruição de tudo que existe se dá por meio de forças antagônicas, pois além dos quatro elementos, existem também a Amizade (ou Amor) que os une e a Discórdia (ou Ódio) que os afasta.

Duas coisas tenho a dizer; às vezes, do múltiplo cresce o uno para um único ser; outras, ao contrário, divide-se o uno na multiplicidade. Dupla é a gênese das coisas mortais, duplo também seu desaparecimento. Pois uma gera e destrói a união de todos (elementos); a outra, (apenas) surgida, se dissipa, quando aqueles (os elementos) se separam. E esta constante mudança jamais cessa: às vezes todas as coisas unem-se pelo amor, outras, separam-se novamente (os elementos) na discórdia do Ódio. Como a unidade aprendeu a nascer do múltiplo, assim geram-se as coisas e a vida não lhes é imutável; na mediada, contudo, em que a sua constante mudança não encontra termo, subsistem eternamente imóveis durante o ciclo(BORNHEIM, 2000, p. 69-70).

Neste fragmento Empédocles apresenta os pontos fundamentais de sua doutrina cosmológica e da existência ciclos eternos de geração e corrupção. Primeiramente, mostra o processo de criação do uno a partir da multiplicidade, e depois da multiplicidade a partir do uno; em seguida, devido uma a ação alternada do amor e da discórdia, este processo se repete sem cessar.

Sobre o duplo nascimento das coisas, Kirk, Raven \& Schofield (2010) destacam que as coisas nascem e (ou/mas) não têm uma vida estável. Dessa maneira, em virtude da incessante alternância entre unidade e pluralidade, elas são imutáveis. Esses autores enfatizam também que é possível entender a ideia de imutabilidade como uma espécie de "reconciliação" de Empédocles com o pensamento de Parmênides:

(...) afigura-se-nos preferível interpretar esse passo como a apresentação de uma hipótese cujo objetivo é reconciliar as noções aparentemente contrárias de que nascimento, morte e mudança em geral existem, e que, no entanto, como sustentou Parmênides, o ser é imutável e permanente ou eterno (KIRK, RAVEN, SCHOFIELD, 2010, p. 301).

O processo de geração e de corrupção, oriundo da ação das forças antagônicas Amor e Ódio é o responsável pela existência de uma 
estrutura de ciclos que se repetem perpetuamente. Tal repetição está imbricada a uma sequência cósmica ininterrupta. Osborne explica a dinâmica desta repetição:

em um momento todas as coisas se unem e tornam-se uma só, e noutro momento tudo se desintegra, transformando-se em pluralidade. Isso explica porque tudo parece trazer em si um tipo de novidade: num certo sentido, são novas as coisas que passam a existir. Elas são "engendradas" e também são transitórias. Mas ao mesmo tempo, nada de realmente novo nasce. As coisas que nascem são apenas fases de uma realidade perene, e essa realidade é "imóvel", no sentido de que, na verdade, nunca deixa de existir. Apenas oscila perpetuamente entre ser uma e ser múltipla (OSBORNE, 2013, p. 25-26).

Conforme Osborne, Empédocles afirma que a situação atual se origina de um estado precedente. Porém acrescenta que as coisas no futuro retornarão ao seu estado anterior.

Não há uma história da criação única e definitiva: tampouco o mundo é estável uma vez que atinge sua forma acabada. Pelo contrário: segue se transformando para sempre. Esta não é a sua "forma acabada"; não houve "elemento original" do qual o mundo teria surgido, como muitos filósofos mais antigos haviam proposto. Ademais, as tendências que provocam as recorrentes inversões são fundamentais: o amor e a discórdia. Eles jamais podem ser eliminados, então não há qualquer perspectiva de um fim para a alternância (Osborne, 2013, p. 33-34).

Quanto à gênese e o destino final dos entes, os fragmentos oito, onze e doze da obra "Da Natureza" abordam a impossibilidade de qualquer nascimento absoluto ou aniquilamento total:

Ainda outra coisa te direi. Não há nascimento para nenhuma das coisas mortais, como não há fim na morte funesta, mas somente composição e dissociação dos elementos compostos: nascimento não é mais do que um nome usado pelos homens" (...) "Os insensatos! Seus esforços são destituídos de longos pensamentos, pois creem que pode ser gerado o que não era ou que alguma coisa possa perecer ou totalmente ser destruída" (...) "É impossível que algo possa ser gerado do que não é, e jamais se realizou nem se ouviu dizer que o que é seja exterminado; 
o que é, sempre estará lá, onde foi colocado por cada um (BORNHEIM, 2000, p. 69).

O nascer e o perecer na perspectiva de Empédocles são impossíveis, pois as coisas não podem vir do nada nem ir ao nada. 0 que os homens chamam de origem e de extinção são apenas momentos da combinação e da separação de substâncias que continuam eternamente iguais e indestrutíveis, oriundas dos quatro elementos originários que constituem as raízes de tudo que existe.

É possível afirmar que a teoria da existência de ciclos contínuos de geração e corrupção encontrada no pensamento de Empédocles constituiu mais um esforço na busca, dentre as várias discussões dos primeiros filósofos, de encontrar e explicar a gênese e a mudança das coisas. Nessa perspectiva, o lugar do tempo é na physis, ele está imbricado às coisas que estão dentro dele, sem início nem fim, num devir perpétuo sobre si mesmo.

\section{A CONCEPÇÃo SUBJETIVISTA DE TEMPO EM KANT}

Na obra Crítica da Razão Pura (1871), Immanuel Kant (17241804) investiga como se dá o processo do conhecimento humano e também busca estabelecer seus limites. Conforme essa abordagem, existem duas vias do conhecimento humano: a sensibilidade, onde os objetos são intuídos, e o entendimento, onde são pensados.

Na primeira parte da referida obra, chamada Estética Transcendental, Kant analisa a sensibilidade, também chamada de faculdade das intuições. Na filosofia Kantiana a intuição corresponde a uma relação direta com o objeto, ou seja, é por meio das intuições que o sujeito apreende as coisas usando os sentidos.

É importante ressaltar que Kant utiliza a palavra estética em seu significado etimológico. Conforme Reale (1990, p. 878.), a palavra estética deriva do grego aìsthesis significa "sensação". Desse modo, a Estética Transcendental corresponde a um estudo das formas de sensibilidade, ou o modo como recebemos as sensações. Kant chama-a de "ciência de todos os princípios da sensibilidade a priori". (KANT, 1983, p. 40).

Essa forma de recepção, apesar de sensível, ocorre de maneira $a$ priori, possuindo universalidade e necessidade, não podendo acontecer 
de outra forma. Nesse sentido, existem duas intuições a priori, o espaço e o tempo. Kant as chama de intuições puras, pois apesar de serem condições da sensibilidade, não estão no mundo físico, mas fazem parte da estrutura cognitiva humana. Kant afirma que se:

... isolaremos em primeiro lugar a sensibilidade separando tudo que o entendimento pensa nela mediante seus conceitos, a fim de que não reste senão a intuição empírica. Em segundo lugar, desta última ainda separaremos tudo o que pertence à sensação, a fim de que nada mais reste senão a intuição pura e a mera forma dos fenômenos, a única coisa que a sensibilidade pode fornecer a priori. No decurso desta investigação, ver-se-á que como princípios do conhecimento a priori há duas formas de intuição sensível a saber, o espaço e o tempo... (KANT, 1983, p. 40).

Espaço e tempo, portanto, não correspondem a realidades materiais, são formas subjetivas de nossas representações. 0 espaço é a forma da percepção externa e o tempo é a formada da percepção interna. Nesse sentido, o tempo é a forma da sensibilidade que abrange tudo o que pode aparecer interiormente, é por meio do tempo que podemos perceber a priori os objetos de forma interior.

Kant, na Estética Transcendental, apresenta detalhadamente sua noção de tempo, utilizando uma série de argumentos (KANT, 1983, p. 44-45):

O tempo é o elemento subjetivo que permite perceber a simultaneidade e a sucessão das coisas, uma condição de experiência; É possível retirar as coisas do tempo, mas não se pode retirar o tempo das coisas; As proposições que dependem do tempo são universais e necessárias, pois o tempo é a priori; 0 tempo é uma intuição e não conceito, pois ele é uno. Nesse sentido, a representação tempo é ilimitada, enquanto um conceito é parcial.

É possível concluir que na perspectiva kantiana o tempo, não deriva da experiência, ele é uma intuição pura, a priori, e não um conceito. Essa intuição serve de fundamento para que a simultaneidade ou sucessão das coisas possa ser percebida. 
O tempo é uma condição do conhecimento humano, a forma da percepção interna. Porém, ao se perceber algo exteriormente, tem-se também a "apercepção" interna, ou seja, dá-se conta de que percebe. Nesse sentido, o tempo se configura como uma forma de sensibilidade tanto interna quanto externa que abarca a totalidade das experiências sensíveis.

Na segunda parte da Crítica da Razão Pura, Kant também atribui ao tempo outra função no processo do conhecimento: o esquematismo. Como foi dito anteriormente, para haver conhecimento é preciso que existam intuições e conceitos, pois estes são os elementos essenciais para sua formação. Os conceitos, diferentemente da sensibilidade, que intui os dados da experiência, vêm do entendimento, que irá pensá-los por meio de suas formas a priori, as categorias.

As categorias do entendimento, segundo Kant (1983), dividem-se em quatro grupos: Categorias de Quantidade (Unidade, Pluralidade e Totalidade); Categorias de Qualidade (Realidade, Negação e Limitação); Categorias de Relação (Inerência e Substância, Causalidade e dependência e Comunidade) e Categorias de Modalidade (Possibilidade Impossibilidade, Existência - Não Ser e Necessidade - Contingência).

0 conhecimento dos fenômenos (objeto do conhecimento), na perspectiva kantiana, ocorre por meio da atividade do entendimento que executa a síntese dos objetos intuídos pela sensibilidade. Nesse processo de síntese dos dados sensíveis surge um impasse que consiste em demonstrar como a intuição sensível acolhe as formas a priori, isto é, como os conceitos que não nascem da experiência se aplicarão a ela?

Essa questão é explicada através de um processo chamado esquematismo. Segundo Kant (1983, p. 105), o esquema é a representação de um processo geral graças ao qual a imaginação oferece sua imagem a um conceito. As categorias apenas serão utilizáveis e só poderão representar um objeto se forem esquematizadas. 0 esquematismo kantiano possui a função de eliminar a heterogeneidade dos dois elementos da síntese, sendo geral como a categoria e temporal como o conteúdo da experiência.

Conforme Vaysse (2012, p. 44), os esquemas são produzidos pela imaginação, uma faculdade também intermediária entre a sensibilidade e o entendimento que se relaciona com seus elementos a priori, 
garantindo uma intercessão entre a receptividade da sensibilidade e a espontaneidade do entendimento. 0 processo realizado pela imaginação se dá através de um elemento puro, comum às intuições e aos conceitos, capaz de conciliá-los. Este elemento puro é o tempo:

Como a condição formal do múltiplo do sentido interno, por conseguinte da condição de todas as representações, o tempo contém na intuição pura um múltiplo a priori. Ora, uma determinação transcendental do tempo é homogênea à categoria (que constitui a unidade de tal determinação) na medida em que é universal e repousa numa regra a priori. Por outro lado, a determinação do tempo é homogênea ao fenômeno, na medida em que o tempo está contido em toda representação empírica do múltiplo. Logo, será possível uma aplicação da categoria a fenômenos mediante a determinação transcendental do tempo que, como o esquema dos conceitos do entendimento, media a subsunção dos fenômenos à primeira (KANT, 1983, p. 104).

O tempo é o responsável pelo esquematismo, que concilia os elementos da sensibilidade com os do entendimento. Na filosofia Kantiana o tempo é subjetivo, uma forma pura da intuição que não existe fora do sujeito, mas uma representação a priori da mente humana. 0 tempo (e também o espaço), portanto, é a condição de manifestação das coisas para nós seres humanos.

\section{TEMPO E CONTEMPORANEIDADE: O PRIMADO INDUSTRIAL E LIQUIDAÇÃO DO SUJEITO}

As observações de Kant acerca da temporalidade no ser humano abrem um importante caminho para se pensar as relações entre tempo e subjetividade, em que se destaca a ideia de que o primeiro está imanentemente atrelado ao indivíduo, pertencendo desse modo a sua constituição fundamental.

Entretanto, se por um lado isso significa que não se pode tratar do tempo fora da esfera da humanidade em si, tal não quer dizer necessariamente que este é uma estrutura a priori inviolável ou incompatível com qualquer horizonte de mudança, ou que escapa imune às variações temporais promovidas pela cultura. 
Partindo dessas premissas, é que podemos pensar, juntamente com as considerações do filósofo francês Bernard Stiegler, as diversas movimentações simbólicas ocorridas nas transformações da sociedade contemporânea, no que o tempo assume uma relevância bastante significativa, principalmente na sua análise de processos referidos aos diversos sujeitos.

Na visão de Stiegler, o mundo regido pela ordem da sociedade hiperindustrial atravessa um momento de profunda perda da individualidade, calcada no narcisismo primário, que desaparece à medida que surgem componentes de hegemonização de seus constituintes, o que, de maneira inevitável, atravessa as formulações gerais sobre o tempo, refletindo-se na composição dos objetos temporais, os quais ele define como sendo formados,

Pelo tempo do seu escoamento - como uma melodia de música, um filme de cinema uma emissão de rádio, etc. um objeto temporal, no sentido husserliano, na medida em que é constituído pelo escoamento durante o qual passa, diferentemente de um objeto como um pedaço de giz, por exemplo, que, pelo contrário, é constituído pela estabilidade, na medida em que não se escoa (p. 45).

Formando dessa maneira, uma importante relação com a própria vivência do ser humano e o modo como este a experienciar, uma vez que há aí uma coligação quanto ao fluxo da temporalidade:

O objeto temporal é muito interessante para quem estuda a consciência na medida em que também ela é, neste sentido, temporal. 0 objeto temporal, por exemplo o filme, tem a mesma estrutura que vós, na medida em que me estais a ouvir, isto na medida em que sois consciências: vós próprios, neste exacto momento, estais a escoar-vos, isto é, a desaparecer para poder aparecer - cada um diferentemente, e cada um numa relação singular com o seu próprio passado, com a sua própria passagem, isto é, também, com o seu futuro (p. 46).

Um objeto temporal se esgota ao mesmo tempo em que aparece, no período de sua duração. De igual maneira, a consciência, e igualmente o indivíduo estão a passar e a desparecer no instante em que 
se mostram. Assim, dentro dessa perspectiva, a percepção do movimento realizado pelos objetos temporais permite estabelecer um elo altamente vigoroso com a atividade humana, em especial no evento de apreensão de tais objetos, em que a mente encontra-se esvaindo-se no ritmo cadenciado pelo aparecer do fenômeno externo.

Tais características, assevera Stiegler, tornam os objetos temporais um ente privilegiado dentro da ordem do capital. E faz com que eles tomem uma forma esquemática e definida dentro dos seus parâmetros, caracterizando-se sobretudo desse modo como objetos temporais industriais, os quais findam por constitui um dos centros de irradiação da lógica de seus produtos:

Hoje, no início do século XXI, grande parte da actividade industrial consiste em produzir objectos temporais que têm como característica aparecerem ao desaparecerem, isto é, na ocorrência, coincidirem no tempo do seu escoamento com o escoamento do tempo da vossa consciência. Quando estais a ver um filme ou um programa televisivo, quando estais a ouvir uma emissão de rádio ou uma canção, o tempo de escoamento do objecto temporal por vós considerado, que a vossa consciência toma como objecto, esse tempo escoa à medida que se escoa o tempo da vossa consciência que nele se enlaça (p. 48).

Dessa maneira, a consciência termina por adotar a temporalidade dos objetos, o que, observar Stiegler, traz consequências expressivas no que diz respeito à individualidade estabelecida no sujeito:

Se vós me escutais neste preciso momento, é porque esperais algo de mim, algo que não tendes: esperais algo da minha consciência na medida em que ela não está sincronizada com a vossa. Ora, as indústrias culturais, e em particular a televisão, constituem uma enorme máquina de sincronização. Quando as pessoas assistem ao mesmo acontecimento televisivo, no mesmo momento, em directo, às dezenas de milhões, senão mesmo centenas de milhões de espectadores, há consciências no mundo inteiro a interiorizarem, adoptarem e viverem os mesmos objectos temporais no mesmo momento. Quando essas consciências, diariamente, repetem o mesmo comportamento de consumo audiovisual, assistem às mesmas emissões televisivas, à mesma hora, e de modo perfeitamente regular - pois tudo é feito nesse sentido -, essas consciências acabam por tornar-se a da mesma pessoa - isto é, todas e nenhuma. (p. 49). 
Na indústria dos objetos temporais, é a externalidade que define os elementos constituintes de nossa compreensão de tempo. Desse modo, aquilo que Stiegler chama de nosso narcisismo primordial começa a desaparecer desde a origem, pois encontra-se atravessado e definido em suas linhas perceptivas fundamentais pelos agentes da ordem da economia e do mercado da cultura, acarretando, assim, uma expressiva reorganização deletéria das estruturas básicas humanas, em nome do consumo plenificado e irrestrito.

À parte os aspectos relativos aos efeitos culturais e políticos desses procedimentos, há consequências inexoráveis destes no que diz respeito à concepção apriorística do tempo por parte dos sujeitos. Ora, se nossa temporalidade se encontra em sincronia com os objetos externos, os quais são igualmente ditados por uma ordem heterônoma, tal significa que este passou a ser apropriado por uma força objetiva, e já não podemos mais reconhece-lo enquanto próprio do sujeito. Porém, considerando-se que o tempo constitui uma de nossas bases perceptivas, toda a nossa condição epistemológica passa a estar sob um código totalmente modificado, cujas consequências se mostram no momento pouco previsíveis.

Eis aí uma questão que não somente deve ser pensada sob um alto prisma filosófico, mas que também ratifica a importância do tempo para o conjunto constituinte humano, que, sem sua própria temporalidade, finda por revelar-se imanentemente alijado do que lhe permite organizar-se em si mesmo.

Há ainda um problema, que devemos elucidar a fim de enveredar nos percursos dessa nova temporalidade do vivido. Se no mundo capitalístico-industrial, não conseguimos mais pensar o tempo em termos kantianos, de que modo ele deve ser concebido? É aí que a retomada de Empédocles se nos apresenta como válida, bem como seus potenciais desenvolvimentos, pois o cenário que se apresenta é de um fluxo temporal marcado por repetições constantes, nos moldes de ciclos, porém cujo processo de aceleração vem se expandindo a ponto de atingir níveis não mais assimiláveis pelos sujeitos, e em cujos resultados se revelam os pontos indicativos de suas alterações sociais e psíquicas. Até onde se rumará em tais caminhos, esta é uma inter- 
rogação em aberto, porém na qual as compreensões dos filósofos aqui enunciadas auxiliam a formular os primeiros horizontes.

\section{CONSIDERAÇões FINAIS}

As proposições filosóficas aqui levantadas apontam para uma ideia de temporalidade que somente no início do século passado ganhou proeminência científica: de nenhum modo, o tempo pode ser pensado somente numa posição absoluta. Sua internalidade possui variações que precisam ser acompanhadas em seu mais arguto movimento.

Obviamente, disso decorre que não se pode apenas pensa-lo em linhas objetivas, tal como fazem os físicos, e sim discutir os simbolismos relacionados a essas variações pelo gênero humano. Logo, é rumando juntamente à compreensão do percurso e do desenvolvimento histórico e técnico da humanidade - no que se avaliam sua práxis e seus mecanismos de mediação cultural - que os efeitos das modificações temporais podem ser adequadamente inferidos no que tange aos sujeitos e o mundo que os circunda.

Assim, concomitante à natureza do tempo, é que podemos falar, em pé de igualdade, de sua simbólica e de sua política, cujas consequências são de importância precípua para o debate social de hoje, a ponto de realizar-se muitas vezes como um ponto central de problematização. Em razão de tudo isso, é que a filosofia precisa estar atenta, a fim de cumprir permanentemente sua tarefa emancipatória de todos os indivíduos também nesse campo.

\section{REFERÊNCIAS}

ARISTOTELES, Metafísica. Coleção “Os Pensadores”. São Paulo: Abril Cultural, 1973. BORNHEIM, G. (Org) Os Filósofos Pré-socráticos. Cultrix, 2000.

DIOGENES LAÉRCIO. Vida e Doutrina dos Filósofos ilustres. Tradução: Mário da Gama Kury. 2. ed. Brasília: Editora da Universidade de Brasília, 1987.

KANT, Immanuel. Crítica da Razão Pura. Tradução: Valério Rohden e Udo Baldur Moosburger. 2. ed. São Paulo: Abril Cultural, 1983. (Os Pensadores).

KIRK, G. S., RAVEN, J. E., SCHOFIELD, M. Os Filósofos Pré-Socráticos. 7a ed. Lisboa: Fundação Calouste Gulbenkian, 2010. 
MONDIN, Battista. Curso de Filosofia. Volume 1. 15a ed. São Paulo: Paullus, 2008.

OSBORnE, Catherine. Filosofia Pré-socrática. Tradução: Márcio Hack. Porto Alegre: L \& PM, 2013.

REALE, Giovanni. História da filosofia: Do Humanismo a Kant-Giovanni Reale, Dario Antiseri. Coleção filosofia. v. 2, 5. ed, São Paulo: Paulus, 1990.

STIEGLER, Bernard. Da miséria Simbólica: I- A Era Hiperindustrial. Lisboa: Orfeu Negro, 2018.

VAYSSE, Jean-Marrie. Vocabulário de Immanuel Kant. Tradução: Claudia Berliner. São Paulo: Martins Fontes, 2012. 